\title{
Relações retóricas e tipos de argumentos: um estudo das correlações possíveis
}

\author{
Juliano Desiderato Antonio \\ Universidade Estadual de Maringá (UEM), Maringá, Paraná, Brasil \\ prof.jdantonio@gmail.com \\ http://orcid.org/0000-0002-9816-5852 \\ Virginia Maria Nuss \\ Universidade Estadual Paulista "Júlio de Mesquita Filho" (UNESP), \\ São José do Rio Preto, São Paulo, Brasil \\ virnuss@hotmail.com \\ https://orcid.org/0000-0002-8606-0463
}

DOI: http://dx.doi.org/10.21165/el.v47i2.1935

\section{Resumo}

Este trabalho tem como objetivo apresentar os tipos de argumentos utilizados em textos argumentativos e as relações retóricas emergentes desses argumentos, assim como as correlações possíveis entre as relações retóricas e os tipos de argumentos. O córpus da pesquisa é formado por 100 redações do gênero resposta argumentativa produzidas para o vestibular de verão/2013 da UEM. A tipologia dos argumentos utilizada na análise tem por base a Nova Retórica, de Perelman e Olbrechts-Tyteca (2005). No que diz respeito à taxonomia das relações retóricas, o trabalho se baseia em Mann e Thompson (1988). Os resultados demonstram correlações recorrentes entre tipos de argumentos e relações retóricas. Isso evidencia a possibilidade de mapear as relações discursivo-argumentativas existentes nas proposições relacionais que emergem das porções textuais do gênero analisado.

Palavras-chave: RST; Nova Retórica; relações retóricas; argumentação.

\section{Rhetorical relations and types of arguments: a study of the possible correlations}

\begin{abstract}
This paper aims at presenting the types of arguments used in argumentative texts and the rhetorical relations emerging from such arguments, as well as the possible correlations between the rhetorical relations and the types of arguments. The corpus of the research is composed of 100 essays of the argumentative response genre produced for the 2013 summer entrance exams of Universidade Estadual de Maringá. The typology of the arguments used in the analysis is based on the New Rhetorics, as proposed by Perelman and Olbrechts-Tyteca (2005), and the taxonomy of the rhetorical relations is based on Mann and Thompson (1988). The results show recurrent correlations between argument types and rhetorical relations. This demonstrates the possibility of mapping discursive-argumentative relations in the relational propositions that emerge from the textual portions of the analyzed genre.
\end{abstract}

Keywords: RST; New Rhetoric; rhetorical relations; argumentation. 


\section{Introdução}

Não seria um equívoco afirmar que os textos argumentativos estão bem ranqueados na lista dos gêneros mais comuns que circulam em nossa sociedade. Sequências argumentativas podem ser encontradas nas esferas jurídica, acadêmica, jornalística, dentre tantas outras. O panorama não é diferente na esfera escolar. Dada a importância social dos textos argumentativos, o trabalho com esses textos merece lugar de destaque na sala de aula e em vestibulares e avaliações nacionais como o Enem.

Partindo dessas considerações, este trabalho tem como objetivo contribuir com a descrição das correlações possíveis que podem ser estabelecidas entre proposições implícitas que emergem da combinação entre partes do texto e determinados tipos de argumentos utilizados por candidatos ao vestibular. Os textos analisados são do gênero resposta argumentativa (doravante RA) que, segundo Menegassi (2011), é constituído por uma afirmação inicial, formada pela retomada da pergunta seguida da resposta a essa pergunta (que é a tese defendida pelo autor), seguida dos argumentos que têm como objetivo convencer ou persuadir o destinatário do texto. $\mathrm{O}$ conceito de argumento adotado neste trabalho é o de Fiorin (2015): raciocínios utilizados para persuasão, convencimento.

Para Mann e Thompson (1988), essas proposições implícitas, também chamadas relações retóricas, são responsáveis pela coerência dos textos. Para se atingir o objetivo proposto no início do parágrafo anterior, em um primeiro momento, são descritas as relações retóricas estabelecidas entre a unidade central (doravante UC) de cada texto do córpus e seu desenvolvimento. No segundo momento, apresenta-se a correlação, com base na Nova Retórica, de Perelman e Olbrechts-Tyteca (2005), entre os tipos de argumentos utilizados no desenvolvimento e as relações retóricas que emergem da combinação entre a UC e o restante do texto.

Além da contribuição descritiva, este trabalho também se justifica pela colaboração que pode dar a professores de ensino médio que ensinam produção textual. Se o aluno produzir seus textos com a escolha consciente dos argumentos utilizados para o desenvolvimento da UC, poderá se sobressair em exames vestibulares e mesmo no Enem na disputa por uma vaga no ensino superior.

\section{Rhetorical Structure Theory - RST}

A Rhetorical Structure Theory (RST) é uma teoria descritiva que tem por objeto o estudo da organização dos textos, caracterizando as relações que se estabelecem entre as partes do texto (MANN; THOMPSON, 1988). A RST parte do princípio de que as relações retóricas que se estabelecem no nível discursivo organizam desde a coerência dos textos até a combinação entre orações (MATTHIESSEN; THOMPSON, 1988).

Do ponto de vista organizacional, Mann e Thompson (1988) destacam que as relações podem ser assim divididas: a) relações núcleo-satélite, em que a informação do satélite é ancilar em relação à informação do núcleo (Figura 1); b) relações multinucleares, em que as informações presentes nos núcleos são do mesmo estatuto (Figura 2). 


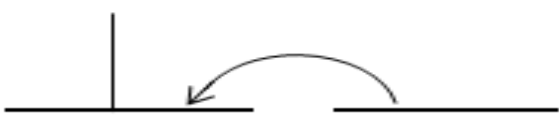

Figura 1. Relação núcleo-satélite Fonte: Mann e Thompson (1988, p. 247)

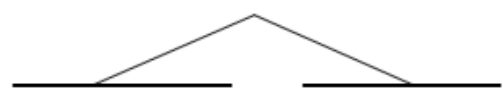

Figura 2: Relação multinuclear Fonte: Mann e Thompson (1988, p. 247)

Os autores-fundadores da RST destacam que as proposições relacionais são de sentido, e não de forma (MANN; THOMPSON, 1983). Do ponto de vista da expressão linguística, isso equivale a dizer que não há necessidade de explicar as relações por meio de conectores. Para identificar as relações, parâmetros funcionais e semânticos devem ser utilizados pelo analista na tentativa de identificar a função de cada parte do texto para produzir o efeito desejado no destinatário do texto.

É importante observar que uma análise baseada na RST é uma análise de plausibilidade. Embora o analista possa ter conhecimento das condições de produção do texto, falta-lhe conhecimento do estatuto das informações na mente do falante. Por isso, não se deve afirmar que uma determinada relação é certamente a que o produtor do texto teve como intenção utilizar, mas sim a relação plausível naquele contexto (MANN; THOMPSON, 1988). No texto-fundador da teoria (MANN; THOMPSON, 1988), os autores propuseram uma lista de 24 relações após a análise de centenas de textos utilizando a RST. Posteriormente, o website da teoria divulgou uma lista com 30 relações.

Os diagramas que representam as análises da RST têm forma arbórea, como pode ser observado na Figura 3, que exemplifica a análise de um texto do gênero resposta argumentativa do corpus deste trabalho. 


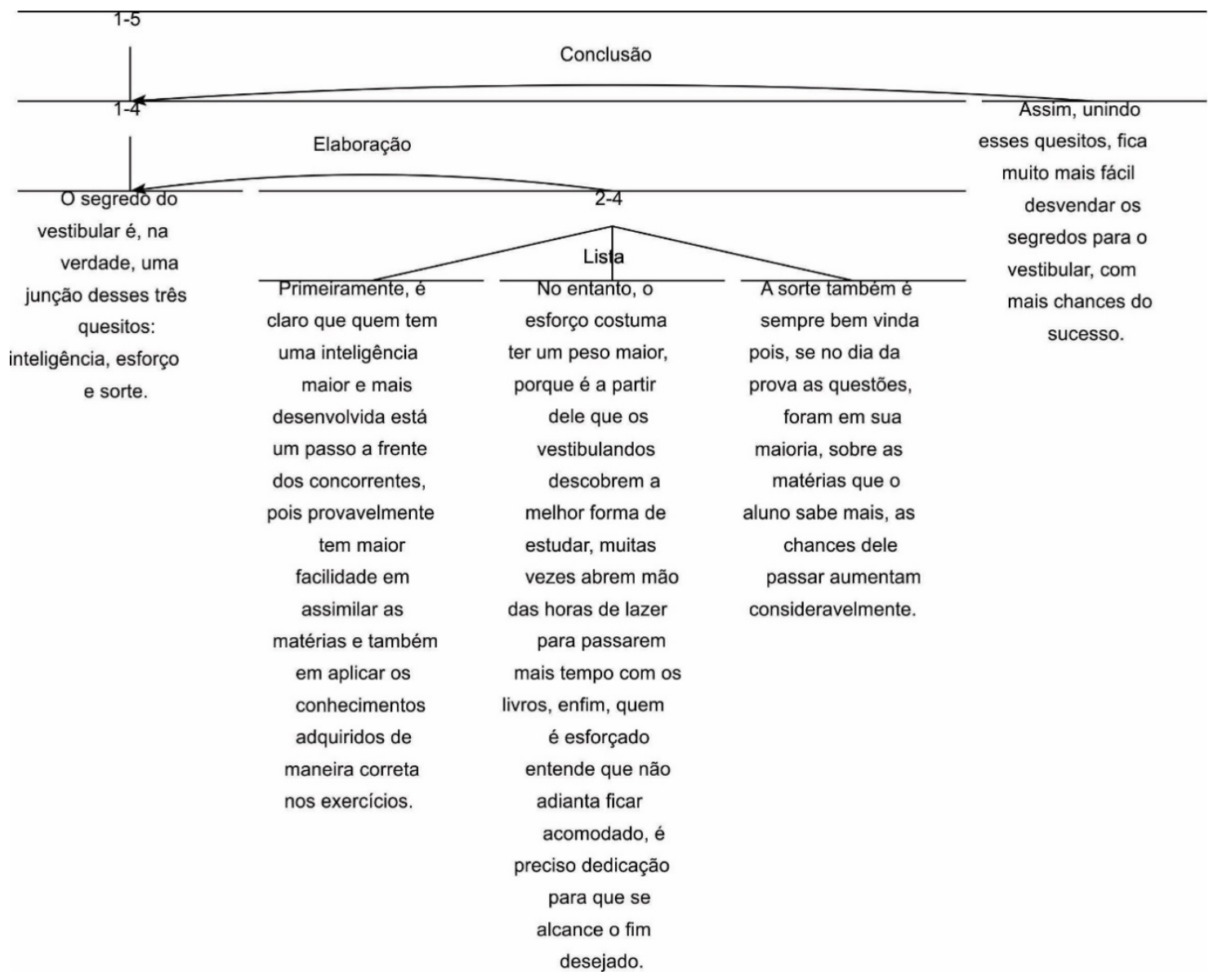

Figura 3. Análise da estrutura retórica de um texto do córpus Fonte: Antonio (2015, p. 3)

O texto em análise é dividido em cinco porções textuais. A porção 1 é a UC do texto. As demais porções são satélite, e, portanto, as setas apontam para a porção 1 . As porções de 2 a 4 estabelecem relação de elaboração com o núcleo. Na relação de elaboração, o satélite acrescenta informações ao conteúdo do núcleo. No caso do texto em análise, na unidade 2, o candidato elabora o fator "inteligência"; na unidade 3, o fator "esforço", e, na unidade 4, o fator "sorte". A relação de lista estabelecida entre as unidades 3,4 e 5 é do tipo multinuclear. A relação de lista é utilizada para ligar elementos comparáveis entre si (MANN; THOMPSON, 1988). Por fim, a unidade 6 é um satélite de conclusão. Essa relação é compreendida por Carlson e Marcu (2001) como um juízo fundamentado, uma inferência, uma consequência necessária ou uma decisão final com respeito à situação apresentada no núcleo.

\section{A perspectiva da Nova Retórica de Perelman e Olbrechts-Tyteca}

A teoria da Nova Retórica instituiu-se a partir do lançamento do Tratado de Argumentação de Perelman e Olbrechts-Tyteca na década de 1970, que reformulam algumas propostas da teoria Aristotélica. Em termos de interação e argumentação, essa distinção representa uma alteração na forma do desenvolvimento dos argumentos. Para Perelman e Olbrechts-Tyteca (2005, p. 203), na argumentação “[...] os sentimentos e impressões pessoais são geralmente expressos como juízos de valor largamente 
compartilhados", sendo que o objetivo maior não seria apenas defender um juízo de valor, mas torná-lo compartilhado e aceito pelo outro.

Conforme Perelman e Olbrechts-Tyteca (2005), para que a argumentação ocorra (argumentação compreendida como um processo complexo que envolve técnicas argumentativas, tipos de raciocínios, tipos de argumentos etc.) é necessário que o orador construa suas proposições (expressões linguísticas que resultam em textos) visando à adesão do auditório. Considera-se, neste trabalho, o orador como sendo o autor/escritor dos textos, e o auditório como o receptor/leitor do texto.

A partir dos raciocínios lógicos e preferíveis, orienta-se toda a argumentação na forma do que se pode chamar de argumentação lógica e/ou dialética e a argumentação retórica. Os raciocínios necessários são formados a partir de silogismos com premissas lógicas, em que a conclusão é obtida a partir da possibilidade quanto aos resultados que tais premissas permitem. Dessa forma, as conclusões obtidas em um raciocínio necessário são tidas como incontestáveis por possuírem um valor de verdade cientificamente comprovado, como em “todo homem é mortal. João é homem. Logo, João é mortal”. Já os preferíveis são criados a partir de silogismos com premissas nas quais a conclusão depende dos valores e crenças do auditório. Como exemplo, a honestidade de determinados grupos ou pessoas, que pode ser assim explicitada "Todo professor é honesto. Maria é professora. Logo, Maria é honesta". A premissa de que todo professor é honesto não se constitui como verdade universal, é uma premissa proposta pelo orador e que pode ou não ser aceita pelo auditório (FIORIN, 2015, p. 17-18). Tal aceitação estará vinculada com o juízo de valor e o conhecimento que o receptor da mensagem possui acerca da honestidade das pessoas que integram a classe "professores". Esses raciocínios podem se desenvolver de três diferentes formas: (i) dedução - em que se vai do geral para o particular; (ii) indução - parte-se do particular para o geral; e (iii) analogia - apoia-se nos valores de semelhança entre as coisas (FIORIN, 2015).

Ainda em termos de argumentos que presidem a argumentação, Perelman e Olbrechts-Tyteca (2005) destacam os argumentos quase lógicos (com base no raciocínio lógico) por um lado, e os fundamentados na estrutura da realidade e os que fundamentam a estrutura do real (com base no raciocínio preferível) por outro. Esses conceitos baseiamse na utilização de recursos retóricos, linguísticos e conceituais que se correlacionam com os tipos de raciocínios supracitados.

Assim, a argumentação com o intuito de persuasão, nos textos analisados, pode ser considerada no âmbito dos raciocínios preferíveis, pois a conclusão da premissa depende da avaliação que o falante realiza acerca dela (não são premissas de raciocínio lógico, mas de raciocínios preferíveis). Desse modo, pode haver mais de uma interpretação possível, o que acarretaria na argumentação a favor de um ponto de vista defendido - a tese, com o intuito de não apenas validar uma tese, mas persuadir o receptor do texto a compartilhar da mesma conclusão obtida pelo autor do texto (FIORIN, 2015).

Fiorin (2015), com base em Perelman e Olbrechts-Tyteca (2005), destaca que a progressão do processo argumentativo é possível por meio da inferência, que pode ser lógica (opera com valores de verdades "incontestáveis"), semântica (opera com o posto e pressuposto do enunciado) ou pragmática (resulta da linguagem pautada nos princípios conversacionais - devidamente abordados por Grice em suas máximas conversacionais). Assim, "Inferência é a operação pela qual se admite como correta uma proposição em virtude de sua ligação (por implicação, por generalização ou [...] por analogia) com outras 
proposições consideradas verdadeiras" (FIORIN, 2015, p. 31). Essas inferências não necessitam estar explícitas no enunciado, mas podem estar presumidas.

Ressalta-se que o processo de leitura de um texto ocorre por meio das inferências (FIORIN, 2015; MENEGASSI, 2010). Isso porque o texto sempre traz em si marcas que "acionam" o conhecimento de mundo do indivíduo, possibilitando que se construa um significado a partir do sentido do texto. Portanto, por meio do conteúdo verbal materializado no texto é possível que o autor/escritor faça com que seu destinatário crie inferências acerca do conteúdo comunicado, podendo aceitar ou não esse conteúdo com base em seu conhecimento de mundo e das inferências realizadas. Salienta-se que tanto as inferências quanto a argumentação podem se basear em diferentes tipos de raciocínios.

No Quadro 1, é possível observar uma síntese dos tipos de argumentos propostos por Perelman e Olbrechts-Tyteca (2005), os quais se situam, em grande parte, no âmbito dos raciocínios preferíveis. Os argumentos lógicos não constam no quadro.

Quadro 1. Tipologia dos argumentos

\begin{tabular}{|c|c|c|}
\hline \multirow{15}{*}{$\begin{array}{l}\text { Argumentos fundamentados } \\
\text { na estrutura do real }\end{array}$} & Implicação e concessão & \\
\hline & Causalidade & \\
\hline & Causas necessárias e suficientes & \\
\hline & Causalidade e sucessão & \\
\hline & Os fatos & \\
\hline & Argumentos do sacrifício & \\
\hline & Argumentum ad consequentiam & $\begin{array}{c}\text { (argumentos "pragmáticos" / de } \\
\text { consequência") }\end{array}$ \\
\hline & \multirow{3}{*}{$\begin{array}{l}\text { Argumentos fundados nas } \\
\text { relações de sucessão }\end{array}$} & $O$ argumento do desperdício \\
\hline & & O argumento da direção \\
\hline & & $\begin{array}{l}\text { O argumento da } \\
\text { ultrapassagem }\end{array}$ \\
\hline & \multirow{5}{*}{ Argumentos de coexistência } & Argumento ad hominem \\
\hline & & Argumento tu coque \\
\hline & & Argumento de autoridade \\
\hline & & Argumentum ad ignorantiam \\
\hline & & Argumentos a fortiori \\
\hline \multirow{4}{*}{$\begin{array}{c}\text { Argumentos que fundamentam } \\
\text { a estrutura do real }\end{array}$} & \multirow{3}{*}{ Os argumentos indutivos } & O argumento pelo exemplo \\
\hline & & O argumento por ilustração \\
\hline & & O modelo e o antimodelo \\
\hline & Argumentum a simili & \\
\hline
\end{tabular}

Outro fator relevante seriam as técnicas argumentativas ${ }^{1}$. Para Perelman e Olbrechts-Tyteca (2005), a argumentação se constitui pela associação ou dissociações de noções em relação ao conteúdo informacional veiculado nos argumentos.

Consideram-se também, para fins deste trabalho, o gênero textual e o contexto de produção dos textos analisados. Ressalta-se que não foram apresentados, no quadro anterior, os argumentos quase lógicos - por não constarem nas análises e resultados.

\footnotetext{
${ }^{1}$ Perelman e Olbrechts-Tyteca (2005) não fazem uma distinção taxionômica entre argumento e técnicas argumentativas. Essa distinção é mais específica em Fiorin (2015).
} 
É necessário salientar que as regularidades e materialidades linguísticas, neste trabalho, foram verificadas sob a perspectiva da RST, fato que permite uma observação mais objetiva entre as possíveis correlações entre essa regularidade (as relações entre as UCs e seus satélites) e os tipos de argumentos propostos pela teoria da nova retórica.

\section{Metodologia}

O córpus da pesquisa é formado por 100 redações do gênero resposta argumentativa produzidas para o vestibular de verão/2013 da Universidade Estadual de Maringá que receberam o seguinte tratamento em pesquisa anterior (ANTONIO, 2015): i) os textos foram digitalizados e segmentados manualmente em EDUs²; ii) quatro anotadores com treinamento em RST anotaram a UC de cada texto; iii) nos casos em que houve discrepância, um superanotador confirmou uma indicação e descartou as demais.

Dentre as 100 redações, foram selecionadas para este trabalho as que apresentam a estrutura típica de uma resposta argumentativa e também os critérios a seguir propostos por Antonio (2015):

(i) a unidade central é a declaração inicial do texto;

(ii) a resposta resume a questão e a unidade central apresenta a estrutura "O segredo do vestibular + cópula + fator(es)" ou a estrutura na qual é levado em consideração mais de um fator]: "O segredo do vestibular + cópula + [junção de] fator(es)";

(iii) a declaração inicial pode ser encabeçada por verbos evidenciais de atitude proposicional como "achar" e "acreditar": "[Eu + verbo evidencial + que] o segredo do vestibular + cópula + [junção de] fator(es)";

(iv) advérbios podem também ser usados, especialmente advérbios asseverativos epistêmicos: "[Eu + verbo evidencial + que] o segredo do vestibular + cópula + [advérbio] [junção de] fator(es)".

Aplicados esses critérios, 35 redações foram excluídas, de acordo com os critérios do Quadro 2.

Quadro 2. Motivos de exclusão

\begin{tabular}{|l|c|c|}
\hline & $\mathbf{N}^{\mathbf{0}}$ & $\mathbf{\%}$ \\
\hline Não apresenta afirmação inicial & 10 & 29,41 \\
\hline Duas respostas & 6 & 17,64 \\
\hline Informações soltas & 5 & 14,7 \\
\hline Responde um fator, mas desenvolve outros & 5 & 14,7 \\
\hline Fatores não desenvolvidos & 3 & 8,82 \\
\hline Seleciona três fatores, mas elege um quarto fator & 2 & 5,88 \\
\hline Tenta desenvolver por antítese, mas se contradiz & 1 & 2,94 \\
\hline Contradição & 1 & 2,94 \\
\hline Tenta justificar, mas não explica justificativa & 1 & 2,94 \\
\hline TOTAL & 35 & 100 \\
\hline
\end{tabular}

\footnotetext{
2 Elementary Discourse Units são "minimal building blocks of a discourse tree" (blocos mínimos de construção de uma árvore discursiva) (CARLSON; MARCU, 2001, tradução nossa). Geralmente, as EDUs correspondem a orações, com exceção de orações completivas e de orações restritivas.
} 
Em seguida, buscou-se determinar a correlação entre os tipos de relações retóricas entre as UCs e seus satélites, e os tipos de argumentos propostos pela Nova Retórica.

\section{Análises e resultados}

As análises realizadas para a identificação das relações retóricas existentes entre as UCs e seus satélites de desenvolvimento apresentaram o seguinte resultado:

Quadro 3. Relações estabelecidas entre a UC e o satélite de desenvolvimento

\begin{tabular}{|c|c|c|}
\hline Relação & $\mathrm{N}$ & $\%$ \\
\hline Justificativa & 21 & 32,3 \\
\hline Elaboração & 15 & 23,07 \\
\hline Evidência & 14 & 21,53 \\
\hline Causa-efeito & 7 & 10,76 \\
\hline Antítese & 6 & 9,23 \\
\hline Concessão & 1 & 1,53 \\
\hline Motivação & 1 & 1,53 \\
\hline TOTAL & 65 & 100 \\
\hline
\end{tabular}

Nos exemplos de texto a seguir, é possível observar construções textuais que apresentam as relações presentes no quadro. Para cada exemplo, apresenta-se também o tipo de argumento retórico-discursivo que é possível correlacionar com as relações de coerência entre a UC e seu satélite.

\section{Texto 01:}

O segredo do vestibular está no esforço, pois quando se tem força de vontade, as pessoas correm atrás, estudam, passam horas e horas em função dos livros, pela busca constante de informações.

Quadro 4. Definição da relação de justificativa

\begin{tabular}{|c|l|l|}
\hline Relação & \multicolumn{1}{|c|}{ Definição da relação } & \multicolumn{1}{c|}{ Intenção do falante } \\
\hline Justificativa & $\begin{array}{l}\text { Condições em Núcleo (N)+Satélite (S): A } \\
\text { compreensão do conteúdo do satélite pelo Ouvinte } \\
\text { aumenta a sua tendência para aceitar que Falante } \\
\text { apresente N. }\end{array}$ & $\begin{array}{l}\text { A tendência do destinatário (D) } \\
\text { para aceitar o direito do falante } \\
\text { (F) a apresentar N aumenta. }\end{array}$ \\
\hline
\end{tabular}

Fonte: Mann e Thompson (1988, p. 252)

O Texto 01 é um fragmento de texto em que a UC está na afirmação inicial "O segredo do vestibular está no esforço" - essa afirmação é, ao mesmo tempo, a especificação da tese defendida. A oração que acompanha a afirmação inicial atua como um satélite, de onde emerge a relação de justificativa. $O$ argumento retórico é fundamentado na estrutura do real, e constitui-se em um argumento de causalidade e sucessão, no qual os fatos são relacionados temporalmente pelo orador, o qual thes atribui uma relação causal - a causa que desencadeia essa sequência de ações é a "força de vontade". Note que o autor relaciona esforço com força de vontade, alegando que a força de vontade desencadeia ações sucessivas temporalmente relacionadas de modo causal. 


\section{Texto 02:}

O segredo do vestibular são os três itens combinados, a inteligência, o esforço e a sorte. A primeira se faz necessária visto que por meio dela torna-se mais fácil a assimilação de conteúdos e o controle pessoal exigido principalmente na hora da prova. Porém, este sem o segundo item não é suficiente, já que ninguém é inteligente o bastante a ponto de dominar todos os assuntos necessários para obter êxito em uma prova de vestibular. Este fato faz com que o esforço torne-se necessário, digo, essencial, por ser o "carro chefe" para a busca de novos conteúdos e materiais, além de dedicação de tempo para a compreensão e fixação dos mesmos.

Por fim, mesmo sendo inteligente o suficiente e esforçado para suprir os déficits [sic] de sua inteligência, a sorte ainda se faz necessária, pois como há um grande volume de conteúdos para serem compreendidos e fixados em um curto espaço de tempo, é quase impossível recordar de tudo no dia da prova e então a última alternativa será apelar para a sorte e responder a questão-fogo, a inteligência, a sorte e o esforço são indispensáveis para a realização de um vestibular.

Quadro 5. Definição da relação de elaboração

\begin{tabular}{|c|l|l|}
\hline Relação & Definição da relação & Intenção do falante \\
\hline \multirow{3}{*}{ Elaboração } & $\begin{array}{l}\text { Condições em N+S: a compreensão da informação no } \\
\text { satélite aumenta a capacidade potencial do D para } \\
\text { compreender o fato, a ação em N. }\end{array}$ & $\begin{array}{l}\text { A capacidade do D para } \\
\text { compreender o fato ou a ação em } \\
\text { N aumenta. }\end{array}$ \\
\hline
\end{tabular}

Fonte: Mann e Thompson (1988, p. 273)

Entre a Unidade Central do texto e seu satélite há uma relação de elaboração. Retoricamente, observa-se um argumento da ultrapassagem, o qual é voltado para o futuro, apresentando etapas sucessivas de acontecimentos que funcionam como suporte para outros acontecimentos, permitindo alcançar uma posição superior à inicial, como no seguinte excerto: "a inteligência é essencial, mas para obtê-la é necessário o esforço". Note que o esforço seria o "trampolim" para a obtenção da inteligência, ou ainda, ações que requerem esforço possibilitam atingir um estágio seguinte, qual seja, o da inteligência.

\section{Texto 03:}

Depender de sorte para ser aprovado no vestibular é tolice, uma aprovação vem do esforço, estudo e controle emocional e não do acaso ou de sorte.

As chances da pessoa de passar no vestibular pelo chutômetro são pequenas, segundo a UFSCar as chances são de $20 \%$ caindo para $4 \%$ caso sejam duas questões e $0,8 \%$ para três questões, mas não é necessário ser super-dotado para ser aprovado, segundo o psicólogo Rubens Riveras Valverde "a força de vontade faz com que muitos adolescentes que não são considerados inteligentes convertam esse sentimento em capacidade para passar".

Quadro 6. Definição da relação de evidência

\begin{tabular}{|c|l|l|}
\hline Relação & \multicolumn{1}{|c|}{ Definição da relação } & \multicolumn{1}{|c|}{ Intenção do falante } \\
\hline Evidência & $\begin{array}{l}\text { Condições em N+S: a compreensão de S pelo D aumenta a } \\
\text { crença de D em N. }\end{array}$ & $\begin{array}{l}\text { A crença do F em N } \\
\text { aumenta }\end{array}$ \\
\hline
\end{tabular}

Fonte: Mann e Thompson (1988, p. 251) 
No Texto 03, entre a afirmação inicial e seu satélite há uma relação de Evidência. Essa elaboração é realizada por meio de diferentes conteúdos informacionais que sustentam a tese com a demonstração de dados que envolvem exemplos de casos que possam servir como referência, uma vez que se trata de instituição de renome e alguém com formação acadêmica específica. Esse tipo de argumento é classificado como argumento de autoridade, o qual apela para o respeito que o auditório possa ter por algo ou alguém. Ainda de acordo com Perelman e Olbrechts-Tyteca (2005), esse tipo de argumento constitui um dos argumentos de coexistência, o qual faz parte dos argumentos que fundamentam a estrutura do real.

\section{Texto 04:}

Em uma disciplinada dedicação e esforço aos estudos árduos que nós, candidatos às vagas de uma universidade, enfrentamos, está o segredo dos vestibulares.

Como consequência a esse empenho, desenvolvemos a inteligência e, indubitavelmente, nossa sorte será obtida. Conforme habituamo-nos ao esforço como estudantes "prévestibulandos" e mantemos altos níveis de confiança quanto à prova, o nervosismo e a ansiedade modificam-se a controle emocional, muito importante durante as provas.

Quadro 7. Definição da relação de causa

\begin{tabular}{|c|l|l|}
\hline Relação & \multicolumn{1}{|c|}{ Definição das relações } & \multicolumn{1}{|c|}{$\begin{array}{c}\text { Intenção do } \\
\text { falante }\end{array}$} \\
\hline Causa & $\begin{array}{l}\text { Condições em N+S: S poderia ter levado o agente da ação em N a realizar } \\
\text { aquela ação, sem apresentação de S; o destinatário poderia não considerar a } \\
\text { ação como motivada ou conhecer a motivação particular; N é mais central } \\
\text { para os propósitos do F ao apresentar a combinação N+S. }\end{array}$ & $\begin{array}{l}\text { D reconhece } \mathrm{S} \\
\text { como a causa da } \\
\text { ação em N. }\end{array}$ \\
\hline
\end{tabular}

Fonte: Mann e Thompson (1988, p. 275)

No Texto 04, há um argumentum ad consequentiam, o qual se constitui por meio de proposições descritivas, avaliativas ou incitativas e que defendem uma ação considerando seus efeitos / consequências. Nesse caso, defende-se a árdua dedicação e esforço, considerando a consequência que advém dessas ações, qual seja, o desenvolvimento da inteligência, segredo para passar no vestibular. A relação entre a UC e seu satélite é de causa-efeito.

\section{Texto 05:}

Existe algum Segredo pra se passar no vestibular? Não, nenhum "Segredo", mas sim o esforço é o responsável pela aprovação.

Quadro 8. Definição da relação de antítese

\begin{tabular}{|c|l|c|}
\hline Relação & \multicolumn{1}{|c|}{ Definição das relações } & Intenção do falante \\
\hline \multirow{3}{*}{ Antítese } & $\begin{array}{l}\text { Condições em N+S: N e S estão em contraste; devido à } \\
\text { incompatibilidade suscitada pelo contraste, não é possível ter uma } \\
\text { atitude positiva perante ambas as situações; a inclusão de S e da } \\
\text { incompatibilidade entre as situações aumenta a atitude positiva do D } \\
\text { por N. }\end{array}$ & D face a N aumenta. \\
\hline
\end{tabular}

Fonte: Mann e Thompson (1988, p. 253)

No Texto 05, existe entre a UC e seu satélite uma relação de antítese. Em termos de argumentação retórica, há um argumento fundamentado na estrutura do real, que se 
realiza como um argumentum tu coque, o qual consiste na desqualificação de argumentos que o autor pressupõe que seu destinatário possua. Nesse caso, o autor desqualifica o item "sorte", de modo a atribuir maior valor para os demais itens (esforço e inteligência).

\section{Texto 06:}

O segredo do vestibular está no esforço. Pois quando se tem força de vontade, as pessoas correm atrás, estudam, passam horas e horas em função dos livros, pela busca constante de informações.

Mesmo não sendo extremamente inteligente, uma pessoa quando se esforça, ela adaptase a tudo, superando até mesmo suas maiores dificuldades, começando a dominar tudo aquilo que estuda-se, aumentando sua capacidade de raciocínio e percepção, passando a derrubar todo e qualquer obstáculo.

Quadro 9. Definição da relação de concessão

\begin{tabular}{|c|l|c|}
\hline Relação & \multicolumn{1}{|c|}{ Definição das relações } & Intenção do falante \\
\hline Concessão & $\begin{array}{l}\text { Condições em N+S: F reconhece uma potencial ou aparente } \\
\text { incompatibilidade entre N e S; reconhecer a compatibilidade } \\
\text { entre N e S aumenta a atitude positiva de D face a N. }\end{array}$ & $\begin{array}{l}\text { A atitude positiva de } \\
\text { D face a N aumenta }\end{array}$ \\
\hline
\end{tabular}

Fonte: Mann e Thompson (1988, p. 254)

No Texto 06, a relação que se estabelece é de concessão. $\mathrm{O}$ argumento utilizado aqui não é fundamentado pela estrutura do real, mas fundamenta a estrutura do real, utilizando as "coisas do mundo" como forma de organização do argumento. Dessa forma, o autor realiza um argumento por ilustração, o qual não se destina à comprovação, mas à abonação de um fato ou conceito que o orador considera como algo já aceito pelo auditório, no caso, a validade consensual que existe para o item "esforço".

\section{Texto 07:}

"Qual o segredo do vestibular: inteligência, esforço ou sorte?". Acredito que um pouco de tudo, você precisa estar preparado, porém, se caso aconteça de você não se lembrar do que estudou, com toda certeza, irá precisar de sorte.

O vestibular não mede somente a sua inteligência, mede também como os seus candidatos agem sobre pressão.

A inteligência e o esforço são necessários na hora da prova, mas será a sorte que ajudará nos momentos em que te der "branco", e manter a calma é o ideal.

E como vestibulando afirmo, se esforce, pois é o seu futuro que está em jogo.

Quadro 10. Definição da relação de motivação

\begin{tabular}{|c|l|l|}
\hline Relação & \multicolumn{1}{|c|}{ Definição da relação } & \multicolumn{1}{|c|}{ Intenção do falante } \\
\hline Motivação & $\begin{array}{l}\text { Condições em N+S: A compreensão de S aumenta a } \\
\text { vontade de D para executar a ação em N. }\end{array}$ & $\begin{array}{l}\text { A vontade de D para } \\
\text { executar a ação em N } \\
\text { aumenta. }\end{array}$ \\
\hline
\end{tabular}

Fonte: Mann e Thompson (1988, p. 274)

No Texto 07, a relação entre UC e satélite é de motivação. Em termos de argumento retórico, o autor utiliza sua própria posição de vestibulando para desenvolver um argumento de autoridade, com o intuito de incentivar, motivar seu destinatário. Esse argumento apela para o respeito que o auditório possa ter por um vestibulando. 
Observando as relações retóricas entre as porções textuais e os tipos de argumentos utilizados, obteve-se a seguinte correlação entre relações e tipos de argumentos:

Quadro 11. Correlação entre relações retóricas e tipos de argumentos

\begin{tabular}{|c|c|c|c|c|c|}
\hline \multirow{2}{*}{$\begin{array}{l}\text { RELAÇÃO } \\
\text { RETORICA ENTRE } \\
\text { UC E SATÉLITE }\end{array}$} & \multicolumn{2}{|c|}{$\begin{array}{c}* \text { Técnica } \\
\text { Argumentativa }\end{array}$} & \multirow{2}{*}{ Tipo de argumento } & \multicolumn{2}{|c|}{ Correspondência } \\
\hline & União & Dissociação & & $\begin{array}{l}\text { Relação } \\
\text { retórica }\end{array}$ & Argumento \\
\hline Justificativa & 17 & & Causalidade e sucessão & 21 & $17(80,9 \%)$ \\
\hline Elaboração & 11 & & $\begin{array}{l}\text { Argumento da } \\
\text { ultrapassagem }\end{array}$ & 15 & $11(73,3 \%)$ \\
\hline Evidência & 08 & & Autoridade & 14 & $08(57,1 \%)$ \\
\hline Causa-efeito & 05 & & $\begin{array}{l}\text { Argumentum ad } \\
\text { consequentiam }\end{array}$ & 07 & $05(71,4 \%)$ \\
\hline Antítese & & 05 & Argumentum tu coque & 06 & $05(83,3 \%)$ \\
\hline Concessão & & 01 & Argumento por ilustração & 01 & 01 \\
\hline Motivação & 01 & & Argumento de autoridade & 01 & 01 \\
\hline TOTAL & 43 & 06 & - & 65 & $49(75,4 \%)$ \\
\hline
\end{tabular}

Dos 65 textos analisados, $75 \%$ apresentaram correlação entre o tipo de argumento e as relações retóricas. Os demais textos, devido ao desenvolvimento realizado pelo falante, acabam construindo outro tipo de argumento - por exemplo, um dos textos com relação de evidência constitui-se um argumento de ultrapassagem. No entanto, mesmo não havendo correlação compatível, por assim dizer, com as demais produções textuais, entre a relação de evidência e o tipo de argumento, a argumentação construída se manteve no mesmo "âmbito argumentativo", ou seja, com associação de ideias e fundamentada na estrutura do real. Com isso, esclarece-se que não houve um afastamento em termos de técnica argumentativa entre os textos analisados, e nem no tipo de raciocínio e base argumentativa, pois a falta de correspondência aconteceu apenas na elaboração dos argumentos que compõem os argumentos que fundamentam a estrutura do real ou que são fundamentados pela estrutura do real.

Reconhece-se que o gênero textual e o comando da pergunta realizada situam os argumentos utilizados no domínio do preferível, com argumentos que são fundamentados pela estrutura do real. No entanto, esse "condicionamento" realizado pelo gênero em questão evidencia a possibilidade de se mapearem as relações discursivo-argumentativas existentes nas relações que emergem das porções textuais.

\section{Considerações finais}

Este trabalho teve como objetivo realizar uma descrição que apresentasse as correlações possíveis entre as relações retóricas que emergem das UCs e seus satélites e os argumentos retórico-discursivos presentes no texto. Com base nos resultados e análises apresentadas, verificou-se que é possível estabelecer uma correlação substancial em $75 \%$ dos textos do córpus.

A relação de justificativa se associa ao argumento retórico fundamentado na estrutura do real e constitui-se em um argumento de causalidade e sucessão, no qual os 
fatos são relacionados temporalmente pelo orador. Já a relação de elaboração se associa ao argumento da ultrapassagem, o qual é voltado para o futuro, apresentando etapas sucessivas de acontecimentos que funcionam como suporte para outros acontecimentos, permitindo alcançar uma posição superior à inicial. A relação de evidência, por sua vez, se realiza por meio de argumento de autoridade, o qual apela para o respeito que o auditório possa ter por algo ou alguém. A relação de causa está ligada ao argumentum ad consequentiam, o qual se constitui por meio de proposições descritivas, avaliativas ou incitativas e que defendem uma ação considerando seus efeitos/consequências. A relação de antítese está associada a um argumento fundamentado na estrutura do real que se realiza como um argumentum tu coque, o qual consiste na desqualificação de argumentos que o autor pressupõe que seu destinatário possua. Em se tratando da relação de elaboração, o autor realiza um argumento por ilustração, o qual não se destina à comprovação, mas à abonação de um fato ou conceito que o orador considera como algo já aceito pelo auditório. Por fim, na relação de motivação, o autor se vale de sua própria posição de vestibulando para desenvolver um argumento de autoridade, com o intuito de incentivar, motivar seu destinatário.

\section{REFERÊNCIAS}

ANTONIO, J. D. Detecting central units in argumentative answer genre: signals that influence annotator's agreement. Actas del XXXI Congreso de la Sociedad Española para el Procesamiento del Lenguaje Natural. Anais... Alicante (Espanha): Sociedad Española para el Procesamiento del Lenguaje Natural, 2015.

AZAR, M. Argumentative Text as Rhetorical Structure: An Application of Rhetorical Structure Theory. Argumentation, v. 13, p. 97-114, 1999.

CARLSON, L.; MARCU, D. Discourse Tagging Reference Manual. Los Angeles: University of Southern California, 2001.

FIORIN, J. L. Argumentação. São Paulo: Contexto, 2015.

MANN, W. C.; THOMPSON, S. A. Relational propositions in discourse. Los Angeles: Information Sciences Institute, 1983.

Rhetorical Structure Theory: Toward a Functional Theory of Text Organization. Text, v. 8, n. 3, p. 243-281, 1988.

The Structure of Discourse and 'subordination'. In: HAIMAN, J.; THOMPSON, S. (Ed.). Clause Combining in Grammar and Discourse. Amsterdam/Philadelphia: J. Benjamins, 1988. p. 275-329.

MENEGASSI, R. J. A escrita na formação docente inicial: influências da iniciação à pesquisa. Signum: Estudos da Linguagem, v. 14, n. 1, p. 387-419, 2011.

PERELMAN, C.; OLBRECHTS-TYTECA, L. Tratado de argumentação: nova retórica. Tradução de Maria Ermantina de Almeida Prado Galvão. São Paulo: Martins Fontes, 2005.

Recebido em: 29/08/2017

Aprovado em: 27/03/2018 